\title{
O Manifesto de 1870 e os Paulistas.
}

\author{
Aureliano Leite \\ Presidente do Instituto Histórico e Geográfico \\ de São Paulo.
}

O papel dos Paulistas na manifestação do ideal republicano remonta às priscas eras de 1788 , à Inconfidência Mineira, com a participação nesse acontecimento de dois filhos da velha Taubaté, o padre Carlos Corrêa de Toledo Piza e seu irmão, o sargento-mor Luís Vaz de Toledo Piza.

Todos sabem qual foi o objetivo dêsses denodados visionarios entre os quais se distinguiram intelectuais do alto coturno de Tomás Gonzaga, Claudio Manuel da Costa, de sangue paulista, e Alvarenga Peixoto e sua mulher Barbara Eliodora, neta de paulista, senhores que já eram dos conceitos inglêses e franceses acerca da democracia e república liberal. Queriam um regime igual ao dos Estados Unidos da America, com a abolição da escravatura negra e uma universidade.

Após muitas décadas, já na tradicional Academia de Direito do Largo de São Francisco, vez por outra, surgia uma voz lembrando que o Brasil constituía em tôda a America a única monarquia.

Antes de 1863, Paulo Eiró compunha o seu Sangue Limpo publicado nesse ano pela Tipografia Literaria da Paulicéia,

*. Discurso proferido na sessão comemorativa do centenário do manifesto republicano de 1870 , realizada no salão nobre desta Faculdade a 3 de dezembro de 1970 .

$23-$ R.F.D. 
onde se entrevê a idéia republicana. Mas onde ela aparece de corpo inteiro é no poema Verdades e Mentiras:

"Morrer pudera, então em terra livre, Sob um poder que só do povo emana, Santo desígnio que as nações meditam, Elo final da liberdade Humana! Porém, passam-se dias, volvem anos, E sempre tronos, sempre soberanos!"

Narra Almeida Nogueira (vol. II de Trads. e Reminiscencias) aquele caso do estudante Martinico Prado, irmão do futuro conselheiro Antonio Prado, que quase arrebentou com certa Sociedade Secreta Brasileira, destinada a apoiar a Monarquia. Aconteceu que, sendo esse estudante incumbido da redação de um memorial histórico e crítico sôbre o movimento político nacional, apresentou um trabalho ardentemente republicano.

Manifestações dêsse tipo ocorreram várias em S. Paulo, antes de 1870.

A célebre recepção, pelos jovens da Academia e o povo, em agôsto de 1868, a José Bonifacio, preclaro senador imperial, ao regressar da Côrte, vitoriosa a sua moção contra o nôvo ministério presidido pelo Visconde de Itaboraí, prova o estado de espírito da Província, a sua inclinação para outro regime.

O neto do Patriarca, ao mesmo tempo seu sobrinho, concluíra a sua Moção de 17 de julho com o candente periodo:

"Amiga sincera do sistema representativo e da Monarquia Constitucional, a Camara lamenta este fato singular, não tem e não pode ter confiança no governo".

Entre os estudantes que apoiaram a promoção do senador de São Paulo, figuram Castro Alves, Afonso Pena, Joaquim Nabuco, Rui Barbosa, Rodrigues Alves e outros.

Mas o Manifesto Republicano de 1870 , cuja redação se atribui a Quintino Bocaiuva, foi sem dúvida o aconteci- 
mento político que provocou entre os paulistas um movimento contínuo, efetivo a conclusivo, pelo ideal republicano.

Em longo artigo estampado em O Estado de S. Paulo, o jornalista Paulo Pestana, da família ilustre de Francisco Rangel Pestana, evocando o primeiro cinqüentenário do histórico manifesto, quando ainda existia um único de seus subscritores - o tribuno, Lopes Trovão, reproduz pormenores que rodearam o lançamento dêsse documento, talvez pouco conhecidos, embora devam constar de publicação de autoria do engenheiro militar capitão Miguel Vieira Ferreira.

Reproduzamos alguns dêsses interessantes pormenores:

"Em fins do ano de 1870, partia do Maranhão, sua terra natal, o engenheiro militar dr. Miguel Vieira Ferreira, com a disposição de iniciar no Rio de Janeiro a propaganda das idéias republicanas. Ao passar por Pernambuco, lembrouse de pedir a opinião de Borges da Fonseca, antigo revolucionário de 1848 e celebre redator do Republico, a respeito dos projetos que trazia. Foi vê-lo e ouvi-lo. O velho democrata lhe falou com esta rude franqueza, que o mesmo engenheiro consignou num pequeno folheto publicado em 1889:

"Não se fie em quem já estiver com a cabeça branca como eu: é gente toda estragada pela monarquia, é gente podre. Mesmo na mocidade a corrupção é grande. No entanto, há na Côrte dois moços, Francisco Rangel Pestana e Henrique Limpo de Abreu, redatores do "Correio Nacional" Esses dois moços eu os tenho por sinceros; são republicanos e não me parecem corrompidos; procure-os".

"Parti para o Rio de Janeiro - narra ainda o dr. Miguel Vieira Ferreira - e aí chegando, logo o "Correio Nacional" deu uma notícia honrosa da minha chegada. Soube que este artigo fôra of erecido à redação por um colaborador, carater muito nobre e elevado da nossa sociedade. O artigo e o ardente desejo que eu tinha de conhecer pessoalmente 
esses dois moços, unicos em quem Borges da Fonseca confiava, e de quem muito esperava, fez-me logo procurá-los em seu escritorio de advocacia e redação. Em companhia de meu irmão dr. Luiz Vieira Ferreira, fiz-lhes conhecer o fim da minha visita e o conceito em que os tinha Borges da Fonseca. Apresentei-lhes a idéia de formar-se um "Clube Republicano" e de criar-se o partido com uma folha que se chamasse "Republica", e tudo feito ostensivamente, quaisquer que fossem as consequencias. Eles asseguraramme ser esse o seu modo de pensar e de alguns outros radicais, mas que eram tão poucos e que tudo se achava tão corrompido, que não pensavam ser possivel encontrar mesmo um pequeno numero de individuos que tivesse a coragem de congregar-se e trabalhar às claras. Disse-lhes ser conveniente experimentar e que por nosso lado, com esse projeto eu tinha vindo e estavamos ambos dispostos a correr todos os perigos; que nós correriamos de bom grado o risco de "cabeça" Eles ficaram de pensar sobre o assunto e separamo-nos.

Poucos dias depois, em nosso escritorio, à rua da Alfandega, esquina da rua dos Ourives, recebemos, de um desconhecido nosso, um cartão convidando para uma reunião republicana que em dia ali fixado, ia celebrar-se ao anoitecer, em uma sala à rua do Ouvidor. O cartão dizia: "Club Republicano". Ficamos muito satisfeitos, e perguntamos ao portador o seu nome e de quem partiu aquele convite. Respondeu-nos: "Chamo-me João de Almeida e o convite vem do escritorio de Limpo de Abreu e Rangel Pestana. Peço-lhe discreção, porque eles não querem que se saiba quem fez o convite". Guardamos este segredo até agora, tempo em que é honroso dizê-lo".

Acrescenta Paulo Pestana ao relato de Miguel Ferreira:

"Ao que ouvimos de Rangel Pestana, que confirmava a narrativa, ele e seu estimado amigo Limpo de Abreu, ambos unidos por solida amizade desde os bancos academicos, aventurando-se a essa empresa, receavam não fosse 
o convite bem aceito pela maioria dos convidados. Iludìram-se. O ideal republicano, avivado pela queda de Napoleão III, em França, a 15 de julho de 1869, já havia conquistado adeptos numerosos e suficientes para formar-se um partido vigoroso".

"A 3 de novembro de 1870, à hora marcada, compareceram ao local designado à rua do Ouvidor $n .^{\circ} 29$, cerca de trinta pessoas, entre as quais algumas de real prestigio politico, quase todas figuras do liberalismo extremado. $\mathrm{O}$ dr. Pedro Ferreira Vianna foi o primeiro a falar, expondo o fim da reunião. Organizou-se a mesa, em seguida, cabendo a presidencia ao dr. Chiristiano Benedito Otoni e ficando como um dos secretarios o dr. Lafayette Rodrigues Pereira, conforme consta da ata. Levantou-se logo a questão preliminar da denominação de "Republicano" para o clube e de "Republica" para a folha. Opinando a respeito, o conselheiro Lafayette, jornalista liberal e posteriormente ministro do imperador, pronunciou-se contra essas denominações, preferindo outros nomes que não despertassem a atenção da policia; mas estendia que à sorrelfa, se devia trabalhar pela República. Ardoroso, Miguel Vieira Ferreira combateu com veemencia semelhante sugestão, reputando-a menos digna e abaixo de um partido reformador".

"Se não houvesse coragem para dizer a palavra "Republica", muito menos haverá para proclamá-la."

Diversos assistentes, como Bittencourt Sampaio, Aristides Lobo e Bandeira Gouvêa, aplaudem tais considerações e, por votação, foram adotadas aquelas denominações. Vendo na assistencia militares - o capitão dr. Luiz Vieira Ferreira, o capitão de fragata Costa Azevedo e o major Floriano Peixoto - o dr. Rangel Pestana levantou-se e lembrou que em vista da resolução anterior, eles iriam cortar sua carreira e talvez sofrer perseguições. Propunha, portanto, se lhes concedesse liberdade para se retirarem, embora continuassem fiéis às suas convicções.

Num belo impulso de civismo o dr. Luiz Vieira Ferreira, capitão de Estado-Maior de Classe, declarou pôr a 
Patria acima de seus proprios interesses e dos da monarquia; e por esse motivo, assinaria o manifesto republicano que ia ser elaborado e acompanhava o partido nascente em todos os seus movimentos. Acrescentou que, no dia que assinasse o manifesto, com a mesma pena assinaria o seu pedido de demissão do serviço do Exercito, o que fêz.

Intervindo no debate, o capitão-de-fragata Costa Azevedo, depois Almirante Barão do Ladário e ultimo ministro da Marinha da Monarquia, exprimiu-se com extrema animação: "Vim a esta reunião — disse — para julgar do que se tratava e ao que se chegaria. Os meus sentimentos de liberdade e patriotismo são muito conhecidos, e em tempo serão comprovados: mas eu tenho esta farda que não estou disposto a deixar e entendo que, trazendo-a, nem devo subscrever o manifesto, nem frequentar estas reuniões. Peço, pois, permissão para retirar-me desde já."

Entre os que também se retiraram estavam o dr. Tavares Bastos, o extremado liberal de "A Província", e o dr. Urbano Sabino Pessoa de Mello, um dos "praieiros" de Pernambuco, em 1848. Riscando suas assinaturas das listas dos fundadores do clube, declararam que "eram radicais, mas não republicanos, por ora".

"Realizadas outras reuniões, efetuou-se a 30 de novembro aquela em que se aprovou e assinou o manifesto do nôvo partido. Para elaborá-lo, foi escolhida uma comissão de quatro membros: Saldanha Marinho, Aristides Lôbo, Quintino Bocaiuva e Flávio Farnese. Redigiu-o no escritório do primeiro a pena elegante e primorosa de Quintino, recém-chegado do Rio da Prata, donde voltava entusiasmado com os incipientes progressos argentinos. Alguns tópicos foram evidentemente inspirados por Saldanha, pois repetem argumentos dêste na brochura "A Política do Rei", publicada anos antes."

Parece-nos curioso lembrar que nenhum paulista, a não serem dois estudantes de Medicina, na Côrte, Antonio de Souza Campos, de Campinas, e Augusto Cesar de Mi- 
randa Azevedo, de Sorocaba, assinaram o manifesto. F. R. Pestana e seu irmão Emílio, também subscritores do histórico documento, não eram paulistas e então residiam na Côrte.

Afinal, o lançamento aos 3 de dezembro de 1870. Pregava a Republica e a Federação. Já em começos de novembro abria-se ali o primeiro Clube Republicano, presidido pelo mineiro Christiano Otoni. O diário "A Republica", dado então à luz da publicidade, estampou-o na íntegra, com tôdas as suas 58 assinaturas. Tudo às barbas venerandas do Imperador.

O órgão "A Republica" resultou da fusão de três fôlhas que sustentavam a propaganda radical: $O$ Correio Nacional, redigido por Limpo de Abreu e F. Rangel Pestana; A Opinião Liberal, fundada por êstes dois jornalistas e transferida a Godoy de Vasconcelos; e o $O$ Radical Acadêmico, redigido por estudantes de Medicina, entre êles Miranda Azevedo, Ramiro Barcelos e Lopes Trovão.

A imperial São Paulo começou a agitar-se. O Interior, também, não tardou. Fundam-se jornais republicanos, aqui, acolá. Os clubes radicais transformam-se em clubes republicanos. Cabe à cidade de Amparo a fundação do primeiro, dezessete dias depois do Manifesto. É que ali agia um grupo de figuras dinamicas, chefiadas pelo mineiro Bernardino de Campos, que, no regime de 89, apenas não alcançaria o seu maior pôsto.

Mas cabe a Piracicaba, ainda cidade da Constituição, o primeiro apoio ostensivo àquela memorável proclamação do irmão mais velho de Prudente, o futuro senador Manuel de Morais Barros, e outras figuras importantes da chamada "Noiva da Colina." Prudente, só aos 1876 aderia ao movimento pela Republica.

O professor Américo Brasiliense, Campos Sales, Bernardino, seu irmão Américo e outros tomam a frente dos trabalhos de propaganda.

Contudo, só um ano e quarenta e cinco dias depois da histórica iniciativa carioca realiza-se na casa de Américo 
Brasiliense, na Capital, uma importante reunião para deliberar sôbre as atividades em preparo, inclusive sôbre o primeiro conclave a reunir-se na fidelíssima Itu.

Brasiliense era o mais categorizado da equipe paulista, pela idade e pelas altas funções desempenhadas dentro da comunhão liberal - deputado provincial e geral e presidente de duas províncias: Rio de Janeiro e Paraiba, além de professor de Direito.

Teve-se o zuidado, nessa primeira convocação dos correligionários, assinada em primeiro lugar por Américo Brasiliense, de declarar que os republicanos não pensavam, por enquanto, em pleitear a abolição da escravatura.

Finalmente, aos 18 de abril de 1873, inaugurava-se a Convenção projetada, que seria presidida por João Tibiriçá Piratininga, das mais idosas figuras da falange e que não chegaria a ver a Republica, pois faleceria em 1888.

Da localização do conclave em Itu, que pouco representa na propaganda do novo regime, procede o equívoco de alguns escritores, como Afonso Taunay e José Maria dos Santos, chamarem a velha cidade - Méca da Republica. Ora, não existe razão para tal. Itu foi escolhida principalmente para aproveitar os festejos da inauguração da Linha Ferrea Ituana e por ser mais acessiva aos convencionais, em maior numero, daquela zona.

Quem pela primeira vez usou do apelido parece que foi o medico baiano Manuel Vitorino, futuro companheiro na chefia do governo de Prudente de Morais. E ele aplicou-o com tôda razão a Campinas. Pertence à culta cidade esse título, pois ela foi por muito tempo o maior centro republicano da Província, excedendo a propria capital. Ali so reuniam, freqüentemente, em torno de Campos Sales, Bernardino, o rabula Francisco Glicerio, Americo de Campos, Alberto Sales e até Prudente de Morais, depois de 1876, sem faltar, uma ou outra vez, o chefe Americo Brasiliense. Dali saia de fato o pensamento e as ordens para as atividades.

Ali José Maria Lisboa editou durante cêrca de dez anos, até 1887, famosos Almanaques Literarios nos quais se estam- 
pava a colaboração de assuntos democraticos assinada por Alberto Sales, Americo de Campos, Rangel Pestana, Campos Sales, Prudente, Miranda Azevedo, Quirino dos Santos, Brasiliense, Bernardino, Lucio de Mendonça, Carlos Ferreira, enfim, todos os maiorais da propaganda.

Itu que se contente com os titulos de "Fidelissima" e "Roma Brasileira", que há muito lhe foram dados.

Uma celebre carta politica, datada de 15 de setembro de 1881, do Visconde de Indaiatuba (J. Bonifacio do Amaral) ao ex-ministro liberal e senador João da Silva Carrão, narra alarmado o republicanismo de Campinas, onde a moda era ser republicano. Acaba implorando faça chegar ao Imperador essa dolorosa informação, sugerindo a Sua Majestade a concessão de titulos nobiliarquicos a varios de seus conterraneos, a fim de contê-los nas suas "convicções monarquicas"... Disso a chusma de baronatos criados então, em Campinas e arredores.

Mas à Convenção de Itu, excluido Taubaté, não compareceu nenhum representante do chamado Norte de São Paulo. O proprio delegado de Taubaté foi um cidadão residente na Capital - Joaquim Taques Alvim.

A explicação para o caso reside na circunstancia dessa zona da Provincia estar muito ligada material e moralmente à Côrte, adorando o Imperador e, sobretudo, a Princesa Isabel.

Pensamos não ficar mal lembrar que a Itu também deixou de comparecer Prudente de Morais. Quem representou Piracicaba foi o seu irmão Manuel de Morais Barros. Houve, todavia, um fanatico que, tempo depois, não admitindo a ausencia do futuro Presidente da Republica, teve a audacia de colocar na ata da reunião, que ainda existe, uma entrelinha com o nome do grande vulto. Por sinal que, com o Manifesto de 1870, passaram-se fatos semelhantes. Lemos em certa publicação - o Dicionario Internacional, como tendo-o subscrito, o que não se deu, o dr. Silviano Brandão, que viria a ser presidente do Estado de Minas. 
A Convenção de Itu funcionou sob a presidencia do já referido João Tibiriçá Piratininga, que, em seguida, expediu a convocação para o I Congresso do Partido, a realizarse na Capital. Destacamos dessa convocação o seguinte topico:

"Constituido aquele sob as condições adotadas, terá a precisa força e autoridade para, estudando a situação em que nos achamos e considerando devidamente as aspirações democraticas da Provincia, resolver as questões de detalhes e adotar providencias e meios eficazes no sentido de satisfazer as vistas do Partido."

Realizou-se esse Congresso de 1 a 3 de julho de 1873 . Presidiu-lhe Americo Brasiliense. O Norte de São Paulo continuou aferrado à Monarquia, mas desta vez além de Taubaté, fizeram-se representar, apesar de por gente estranha, Paraibuna, pelo Dr. João Manuel de Lima e Silva, advogado, no fôro de Rio Claro, e São José dos Campos, pelo tribuno famoso Luiz Gama, homem da Capital.

Para estudar projeto de organização politica com base na federação e plena autonomia dos municipios designou-se uma Comissão Permanente, então escolhida, presidida por Piratininga e secretariada pelo futuro Consul em Napoles, Americo de Campos.

Quanto à abolição da escravatura, continua no mesmo tom o manifesto publicado em seguida:

"Fique portanto bem firmado que o Partido Republicano, capaz de fazer a felicidade do Brasil quanto à questão do estado servil, fita desassombroso o futuro, confiado na indole do povo e nos meio de educação, os quais unidos ao todo harmonico de suas reformas e do seu modo de ser hão de facilitar-lhe a solução mais justa, mais pratica e moderada, selada com o cunho da vontade nacional."

Por fim, da cidade de Campinas, a verdadeira Meca da Republica, lança a Comissão Permanente um projeto contendo as bases da Constituição do futuro Estado de São Paulo, projeto da autoria de Americo Brasiliense, que seria 
estampado em seu livro Os Programas dos Partidos, lançado em 1878.

O segundo Congresso reunir-se-ia, ainda na Capital, em abril de 1874. Agitava-se em todo o Imperio a questão religiosa. O Congresso toma parte no entrevero. Corre em auxilio dos que na Côrte - Saldanha Marinho, Quintino, Tavares Bastos, se manifestam contra a cleresia - solidariza-se com o governo defendendo o princípio fundamental da distinção entre o Estado e a Igreja. No manifesto lançado a publico, prega-se a liberdade de cultos, separação da Igreja do Estado, ensino secular à parte do religioso, casamento civil, registro civil e secularização dos cemiterios.

Nos anos de 1875 a 1877, não se reune o Congresso, ficando assentada uma nova convocação quando os interesses partidarios o exigissem. Em compensação, os republicanos comparecem aos pleitos para as camaras municipais, juizes de paz e eleições gerais. Alcançam algumas vitorias.

Nas eleições para a Assembléia Provincial, já sob a lei de 1875, o Partido pleiteia uma cadeira. É candidato Americo Brasiliense, guerreado pela imprensa liberal, que acusa o representante de seu partido nas assembléias passadas de traição a seu credo. Não consegue eleger-se. A Provincia tinha direito a nove cadeiras; Brasiliense alcançou na votação o decimo-primeiro lugar.

Concomitantemente, funda-se a Provincia de São Paulo, diario que vem prestar à campanha grande estimulo. Francisco Rangel Pestana, que, com seu irmão Emilio subscreveu o Manifesto de 1870, muda-se para São Paulo, sendo entregue a ele e a Americo de Campos a direção do prestigioso orgão, administrado por José Maria Lisboa.

A mocidade acadêmica não ficou estranha ao comportamento dos paulistas. Agora, não são mais manifestações esporadicas como as de Paulo Eiró e Martinho Prado. Segue de perto a voz de comando do velho lider Professor Américo Brasiliense. Durante todo o longo espaço de tempo que vai 
do Manifesto de 1870 à Proclamação de 1889, as gerações se substituem mas o ideal permanece e se transmite às novas. Os rapazes entregam-se à luta, organizando clubes e mantendo jornais que circulam dentro e fora do velho Convento das Arcadas. Já em 1871, imprimem o semanário A Propaganda, seguido de $O$ Rebate, em 1874. Em 1876, criam a Republica, redigida por, entre oútros, o futuro senador federal Pinheiro Machado e Brasilio Rodrigues dos Santos. Depois, o Federalista, sob a redação de Pedro Lessa, Alberto Sales e Alcides Lima. De novo A Republica, em 1881, redigido pelo mesmo Pedro Lessa e Alberto Sales, além de Ubaldino Amaral, Aristides Maia e Antonio Mercado. Finalmente, um segundo $O$ Rebate, fundado pelo gramático Julio Ribeiro, autor da Bandeira Paulista e também de romance que ao tempo ofendeu a pudicícia de nossa sociedade - Carne.

Ao aproximarem-se, em 1877, as novas eleições para a Assembléia Provincial, a Comissão Permanente, após consulta aos correligionarios, indica para ela seis candidatos: Campos Sales, Rangel Pestana, Prudente de Morais, Martinho Prado, F. Quirino dos Santos e Luís Pereira Barreto. O nome de Americo Brasiliense não alcançou o quorum necessario.

Pestana e Barreto, alegando como principal motivo não serem paulistas, recusaram a indicação. Em nova previa, manteve-se o nome de Pestana. Do pleito sairam vitoriosos apenas Prudente, Cesario Mota, que entrou no lugar de Barreto, e Martinho Prado. Foram os primeiros deputados republicanos da Provincia.

Mudando-se a situação política do Imperio com a subida, em 5 de janeiro de 1878 , ao poder do gabinete dirigido pelo Visconde de Sinimbu, de que veio a fazer parte o antigo subscritor do Manifesto de 1870, Lafayette Rodrigues Pereira, inumeras consultas chegaram à Comissão Permanente a respeito da atitude que os republicanos deviam adotar. Pensaram alguns que esse Gabinete, diante do gesto de 
Lafayette, de Cristiano Ottoni e outros, voltando ao ninho antigo, fosse digno de apoio. Refira-se de passagem que Prudente de Morais, segundo Silveira Peixoto, foi convidado pelo Visconde de Sinimbu para integrá-lo, repelindo o convite.

Não querendo a Comissão tomar a responsabilidade de um conselho, pareceu-lhe de melhor política convocar um Congresso para deliberar a respeito.

A 10 de março de 1878 celebrou a sua primeira sessão plenaria. O Norte de São Paulo não mandou representantes. Em manifesto lançado a 11 de março do mesmo ano, ainda que sem mencionar o nome do grande jurista mineiro, os seus lançadores condenam-lhe o gesto incompreendido.

"Fortalecidos pelo nosso direito e pela nossa consciencia apresentamo-nos perante os nossos concidadãos arvorando resolutamente a bandeira do Partido Republicano Federativo". Americo Brasiliense é o ultimo a assiná-lo.

Mas assina ainda, e pela ultima vez o faz em documento politico durante a propaganda, a publicação inserida em A Provincia de São Paulo, contra a Tribuna Liberal, redigida por Bento F. de Paula Sousa, em intimas relações com o presidente João Batista Pereira, por sinal, obrigado a demitir-se daí a pouco, por motivo de morticinio em São João Batista do Rio Verde e agitação na Capital, com repercussão em Mococa, Franca, Botucatu e Avaré.

Com intuito de apaziguar os animos, D. Pedro II visita a Capital, onde é recebido sob o dobre dos sinos para a missa das vítimas dos conflitos. O Correio Paulistano, orgāo dos conservadores ligados a Antonio Prado, que nesse momento tem o apoio dos republicanos, amanhece tarjado de luto.

Nas eleições gerais de 1878, para a Camara e Senado, nas vagas do Marquês de São Vicente e Visconde de Caravelas, nas primeiras, os republicanos são derrotados e, nas segundas, não comparecem às urnas. 
Nesse ano, Americo Brasiliense, que vem visivelmente perdendo o seu prestigio de chefe do Partido, sendo substituido na direção pelo grupo de Campinas - Campos Sales, Prudente, Bernardino, Glicerio, Cerqueira Cesar e outros, lança o seu livro Os Programas de Partido e o Segundo Imperio (diria melhor Segundo Reinado), no qual prega, concluindo a primeira parte do volume:

“O país já não tem fé e confiança nos homens de Estado de ambos os partidos (Liberal e Conservador), nos seus programas e nas instituições. É de esperar que as idéias republicanas largamente derramadas nas populações de Minas, Pernambuco, Bahia, Rio de Janeiro e Rio Grande do Sul, e como que paralisadas nesses pontos com a ascensão da politica liberal, se agitem e os homens que aí as professam, se organizem em partido em periodo bem proximo, tomando, por exemplo, a Provincia de São Paulo".

$O$ velho chefe perdera o prestigio mas conservava a fé republicana.

Com exceção da legislatura de 1880 a 1881, em todas as mais, até a de 1888 a 1889 , os Republicanos mantêm seus representantes na Assembléia Provincial, mas, só em 1884, logram eleger os primeiros deputados gerais. São eles: Prudente de Morais e Campos Sales.

Afonso Celso, em Oito anos de Parlamento, editado em 1901 e reeditado em São Paulo em 1928, teceria conceitos desprimorosos contra os dois deputados paulistas, concluindo que ninguém poderia acreditar estivessem ali dois futuros presidentes da Republica. Tivemos em mãos um exemplar da $1 .^{a}$ edição que pertenceu a Prudente, no derradeiro ano de sua preciosa existencia na amada Piracicaba. Aquele que José do Patrocinio qualificou de Santo Varão da Republica comentou-o do começo ao fim, mostrando as injustiças do autor.

Após lapso de nove anos, aos 1887, de 30 de maio a $1 .^{\circ}$ de junho, os republicanos promovem na Capital o der- 
radeiro de seus Congressos partidarios, que é presidido por Prudente de Morais.

De par com a ideologia republicana e federativa, assim como da abolição, debate-se audaciosa tese separatista, manifestando-se a favor, entre outros, Campos Sales, seu irmão Alberto Sales, Martim Francisco $\left(3^{\circ}\right)$, o mineiro Horacio de Carvalho. Contra, figuram, entre outros, o jovem Julio Mesquita e F. Rangel Pestana.

Tacito de Almeida, irmão do poeta Guilherme de Almeida, logo após a Revolução de 1932, em seu livrinho - $O$ Movimento de 1887 - - exploraria em termos candentes a tese debatida. Argumentaria até com o fato de não paulistas, como o grande Saldanha Marinho e Ubaldino do Amaral, se mostrarem separatistas.

Crescem daí em diante o animo e a esperança dos partidarios do novo regime.

As Camaras Municipais de Campinas, São João da Boa Vista, São Simão, São Vicente e Itatiba, manifestam-se contra a Monarquia, principalmente contra a possibilidade de um terceiro reinado, sob a direção da Princesa Isabel, casada com um estrangeiro.

Rodrigues Alves, na presidencia da Provincia, manda processá-las.

A Assembléia Legislativa, sob a chefia do conselheiro Antonio Prado, ex-ministro dos Estrangeiros, que já andava de namoro com os republicanos, apoia o requerimento dos deputados Bernardino de Campos, Prudente e Campos Sales, que Lucio de Mendonça apelidaria de "Gambeta do Brasil", contendo censura contra o presidente Rodrigues Alves. Adiante-se que dois dias após o 15 de novembro, Prado e seus amigos adeririam espetacularmente ao novo regime, em sessão magna, no velho Teatro São José.

Atingimos 1888. O grupo de chefes, um tanto à margem Brasiliense, espalha-se por toda a Provincia, promovendo comicios em teatros e praças publicas. Francisco Glicerio 
sofre em São José do Pio Pardo um atentado de que escapa incolume. Silva Jardim adere ao grupo, fazendo ouvir em varias cidades a sua voz de excelente tribuno. Ano e pouco depois de 15 de novembro de 1889, seria tragado pelo Vesuvio, deixando como legado politico a celebre declaração de que "não era esta a Republica que sonhei".

Aproveitando-se da exaltação entre os abolicionistas pela Lei Aurea, é lançado manifesto em que se declara: "Queremos a Republica, como solução mais pronta à crise social".

O orgão A Provincia de São Paulo já não está só na defesa do credo. Surgem A Platéia de Araujo Guerra, A Cidade de Santos, de Martim Francisco, O Rebate, de Julio Ribeiro, e, antes deles, $O$ Diario Popular, fundado pelo português José Maria Lisboa.

Levanta-se na Capital o $17 .^{\circ}$ Batalhão de Linha. Ě o calor do novo regime que se aproxima. Seguem-se manifestações de rua nas quais a Monarquia é apupada e a Republica vivada.

Finalmente. 1889.

Saldanha Marinho, lá da Côrte, como presidente do Partido Nacional, convoca congresso a realizar-se em São Paulo, o qual não chega a reunir-se.

Quintino Bocaiuva recebe merecidas homenagens dos paulistas.

A Policia inicia violencias. O gaucho Diana Terra é impedido de promover comicio no largo da Sé.

A 31 de agosto fere-se a derradeira eleição da Monarquia para a renovação da Camara Baixa, dissolvida pouco antes.

Os republicanos, que cuidam mais da conspiração que do pleito, acabam totalmente derrotados.

Aos 6 de novembro, Campos Sales, segundo ele proprio narra, recebe a primeira comunicação feita por Aristides Lobo, de que se acha proximo o estouro na Côrte. 
Francisco Glicerio é enviado ao Rio como delegado dos correligionarios. Daí a pouco, Medeiros e Albuquerque chega à Capital trazendo a confirmação da marcha dos acontecimentos, mandada por Aristides e Quitino Bocaiuva. Apesar de que Aristides fôsse tido como um grande visionario por Brasiliense e Pestana, nessa mesma noite reuniram-se os republicanos na casa de L. Pereira Barreto, à rua Visconde do Rio Branco. São estes: Barreto, Campos Sales, Rangel Pestana, Melo Oliveira, Vitorino Carmilo. Francisco Lobo, Miranda Azevedo, Adolfo Gordo e M. Lopes de Oliveira. Segunda reunião realiza-se na casa de Lopes de Oliveira, na rua do Ipiranga, 31. Brasiliense sempre ausente.

Campos Sales recebe aviso de que até nove ou dez do mês, dia do embarque do Batalhão 22 de Infantaria para o Norte, "alguma coisa sumamente grave se passará".

Mas a 9 e 10 nada acontece. Ansiosos, aguardam mais cinco dias.

Afinal, aos 15 de novembro, após os primeiros avisos do que ocorre na Corte, já Prudente de Morais, que se achava em Piracicaba, convocado por telegrama, não se conseguindo a coadjuvação de Brasiliense, os chefes republicanos adotam medidas que a grave e magna situação exige.

Assim, couberam ao Presidente Brigadeiro Couto de Magalhães os dias de agonia do segundo reinado, os quais se findaram na Capital pela tarde alvorotada de 16 de novembro.

E é aclamado para dirigir a Provincia, transformada em Estado, nos seus primeiros dias, um triunvirato de que fazem parte Prudente, como Presidente, e como membros o jornalista F. Rangel Pestana e o Coronel Joaquim de Souza Mursa, diretor da Fabrica de Ferro do Ipanema.

E' a Republica nasceu para seguir o destino a que os brasileiros haviam de levá-la. 
Meus senhores:

David Hume, autor de admirada obra sobre a Inglaterra, ensina que a Historia é o esforço disciplinado para dissecar o passado, cientificamente, ou seja, criticamente.

Não foi o que tivemos o proposito de fazer. Limitamonos a voltar para o passado da propaganda republicana na Provincia de São Paulo, não armados de um bisturi, mas com os olhos abertos e a sinceridade recomendada por Langroi et Seighobos, na Introduction aux Etudes Historiques. 